\title{
Ilhas de calor e conforto térmico na cidade de Salvador (BA)
}

\author{
Islands of heat and thermal comfort in the city of Salvador (BA)
}

Bárbara Carlos Ferreira ${ }^{1}$; Laila dos Santos Oliveira ${ }^{1}$; André Luiz Dantas Estevam ${ }^{2 *}$

\begin{abstract}
${ }^{1}$ Universidade Estadual da Bahia -UNEB, Campus V, Santo Antônio de Jesus, Bahia, Brasil, 44.570-000, barbaracarlosferreira28@gmail.com: https://orcid.org/0000-0002-3781-9197; lailaoliveira003@gmail.com; https://orcid.org/0000-0002-2510-9892

2*Departamento de Ciências Humanas, Universidade Estadual da Bahia -UNEB, Campus V, Santo Antônio de Jesus, Bahia, Brasil, 44.570-000, alestevam@uneb.br; https://orcid.org/00000002-1114-2982. (Autor correspondente)
\end{abstract}

\section{Resumo}

O objetivo deste trabalho é analisar os fatores atuantes para a formação das ilhas de calor na cidade de Salvador. Essa pesquisa analisou os impactos da urbanização para ocorrência deste fenômeno. Como as ilhas de calor estimulam o stress térmico positivo nas pessoas e residências no sitio urbano repercutindo-se diretamente no conforto térmico. Estes fenômenos consistem em anomalias térmicas no clima urbano oriundos do processo de intensificação das construções e a substituição de áreas arborizadas por zonas de concreto e asfalto. Essas anomalias térmicas desencadeiam alterações bruscas no microclima da metrópole. O método de abordagem consistiu na análise de diversas literaturas como artigos, teses e dissertações com ênfase para o tema. Foram analisadas as temperaturas de superfície das coberturas de asfalto, concreto, solo desnudo e árvores com sombra. Observou-se as correlações entre o comportamento térmico das superfícies citadas e as temperaturas do ar para a análise das localidades que detenham ilhas de calor e ilhas de frescor. Para além disto foi abordado neste artigo as interações entre a sensação térmica nas pessoas e os efeitos das ilhas de calor em fevereiro do ano de 2019 na cidade de Salvador.

Palavras-chaves: Ilhas de calor; Urbanização; Microclima; Sensação Térmica.

\begin{abstract}
The objective of this work is to analyze the factors that are active in the formation of heat islands in the city of Salvador. This research analyzed the impacts of urbanization for the occurrence of this phenomenon. As the heat islands stimulate positive thermal stress in people and homes in the urban area, directly impacting thermal comfort. These phenomena consist of thermal anomalies in the urban climate arising from the process of intensifying construction and the replacement of wooded areas with areas of concrete and asphalt. These thermal anomalies trigger sudden changes in the metropolis' microclimate. The approach method consisted of the
\end{abstract}


analysis of several literatures such as articles, theses and dissertations with an emphasis on the theme. The surface temperatures of asphalt, concrete, bare soil and shaded trees were analyzed. The correlations between the thermal behavior of the aforementioned surfaces and the air temperatures were observed for the analysis of the locations that have islands of heat and islands of freshness. In addition to this, the interactions between the thermal sensation in people and the effects of heat islands on February of 2019 in the city of Salvador were addressed in this article.

Keywords: Heat islands; Urbanization; Microclimate; Thermal Sensation

\section{Introdução}

A cidade de Salvador, possui uma área de $693.831 \mathrm{~km}^{2}$, sua população está estimada em 2.872.347 habitantes, conforme IBGE (2018). Por ser uma grande metrópole, o processo de urbanização sem planejamento e as ações antropogênicas proporcionaram para a cidade o fenômeno das ilhas de calor.

O clima detém características semelhantes às músicas. Conforme Monteiro (1971) as linhas do tempo atmosférico constituem verdadeiras partituras musicais, nos quais os símbolos nos intervalos de tempo representam os acordes. O clima apresenta diferentes ritmos enquadrados em escalas de períodos mais ou menos intensos, períodos monótonos outros mais perturbados. Períodos regidos pelas entradas de energia no sistema atmosférico proveniente da penetração de energia na atmosfera.

A atmosfera detém estados diversos marcados pela mutabilidade, configurados por estados momentâneos. Monteiro (2001), denomina a atmosfera como a mais dinâmica das esferas terrestres. Neste contexto, as intervenções antropogênicas bruscas impõem ao sistema climático local, interferências no circuito atmosférico que implicam em respostas agudas por parte dos elementos do clima.

Centros densamente urbanizados e mal planejados como a cidade de Salvador passam por consequências climatológicas. Dentre elas o aumento de calor, poluição dor ar, cortes de árvores que no clima urbano são essenciais para a qualidade do ar e conforto térmico e a canalização de rios. Tais intervenções produzem no sítio urbano uma paisagem constituída de muito concreto. O que pode ser observado através dos prédios comerciais, das indústrias, residências, da pavimentação das ruas e a impermeabilização do solo. Consequentemente, criam-se áreas 
com maior absorção de calor que são as ilhas de calor, resultante das intervenções sem o planejamento adequado para os usos dos solos.

O objetivo deste artigo é compreender a dinâmica de uso do solo e seus impactos para a variabilidade térmica no sitio urbano de Salvador. Discute-se neste trabalho os impactos que as variabilidades das temperaturas geram em virtude da expansão das áreas construídas e como a extensiva pavimentação induz a elevação anômala da temperatura do solo e do ar no clima local da cidade.

O clima urbano é resultado das interações entre as ações antropogênicas e a paisagem urbana. Geram-se alterações no relevo, pavimentação e encapsulamento dos rios, redução brusca das áreas arborizadas e impermeabilização dos solos. Neste contexto, o clima urbano sofre interferências profundas advindas da resposta no ambiente urbano da introdução de alterações drásticas nos elementos da natureza. Portanto, a partir da análise geográfica do clima e suas variáveis é de fundamental importância diagnosticar essas alterações e seus impactos sobre a qualidade de vida das pessoas para nortear as políticas públicas que visam melhorar a saúde das pessoas. Tendo em vistas que alterações bruscas nas temperaturas no decorrer do verão induzem o stress térmico positivo que tem impacto direto sobre a qualidade de vida das pessoas, sobretudo àquelas que detém problemas crônicos de saúde como hipertensão arterial e problemas respiratórios.

Outro aspecto relevante na detecção das ilhas de calor é o grau de reflexão das superfícies. O albedo detém alto grau de relação com os materiais empregados nas edificações, quanto menor for o grau de reflexão das superfícies maior será o calor emitido pela massa de materiais produzindo agravamento da ilha de calor.

\section{DISCUSSÃO TEÓRICA: EFEITOS DA URBANIZAÇÃO E TRANSFORMAÇÕES DO ESPAÇO URBANO}

As urbanizações das grandes metrópoles sempre foram necessárias para o desenvolvimento do país, para tal processo ser progressivo foi necessário construções e implantações de centros indústrias próximas aos sítios urbanos. Modificou-se toda a dinâmica do espaço natural. "As tendências mais recentes da urbanização em Salvador apontam para um aprofundamento da 
concentração de capital, que aparece na forma de uma proliferação de shopping centers e de uma concentração dos supermercados...” (PEDRAO 2005, p. 2)

A urbanização provocou transformações de alto impacto nos espaços efetuados devido à ausência de políticas públicas de planejamento. Desencadeou-se nos centros urbanos extrema alta das temperaturas das superfícies devido à ausência de árvores, rios e demais elementos naturais da flora que foram substituídos por grandes prédios pavimentações e pela impermeabilização do solo, assim como a canalização de rios.

As edificações e construções dos sistemas viários nos sítios urbanos, ocasionaram um efeito climático de elevação do calor nessas áreas. Processo este denominado de ilhas de calor que é o aumento de calor ocasionados pela má circulação dos ventos, poluição do ar e falta de arborização. Estes fenômenos foram amplamente estudados por Howard Luke (1833) e Garland (2010).

Segundo Lombardo (1985) o desordenamento que se dá ao uso do solo no sítio urbano, gera dificuldades na implantação de infraestruturas e desconforto ambiental térmico, acústico, visual e de circulação.

A cidade de Salvador do século XX sendo analisada de um modo mais urbanista, identificase uma cidade mal planejada de ruas estreitas e com corredores de casas e prédios desfavoráveis a circulação de vento e até mesmo a passagem de luz solar em algumas áreas (COSTA, 2015). Tais aspectos favoreceram para que atualmente as ilhas de calor desencadeiem maior desconforto térmico. Outro aspecto importante a ser considerado é o elevado fluxo de veículos que contribuem para alta das temperaturas via aquecimento do ar e lançamento de $\mathrm{CO}_{2}$ ao longo das avenidas e demais sistemas viários.

Segundo Neri e Estevam (2018) as causas das formações das ilhas de calor, ocorrem pelas massas de edificações, já que as vias públicas absorvem grandes quantidade de radiação solar, já que não constituem solo sem pavimentação e não fazem mais o processo de evapotranspiração para amenização do calor.

...grande armazenamento de calor durante o dia devido às propriedades térmicas (condutividade térmica e capacidade térmica) dos materiais de construção utilizados nos ambientes urbanos com 
consequente re-emissão para a atmosfera durante a noite e diminuição do fluxo de calor latente devido ao aumento de superfícies impermeáveis. (SANTOS et al. 2016 p.2)

\section{URBANIZAÇÃO E CLIMA URBANO}

Um dos principais estudos mais recentes sobre a urbanização e clima urbano ocorreu no ano de 1833 por Luke Howard, após a $2^{\mathrm{a}}$ Revolução Industrial, na cidade de Londres, a cidade em seu miolo urbano, local de concentração de grandes fábricas. Tais processos sem o devido planejamento para a cidade desencadeou poluição intensa do ar. Essas condições propiciaram a formação de um clima particularmente local com altas temperaturas em determinadas áreas. Gerou-se assim os primeiros estudos sobre as ilhas de calor.

As áreas industriais se concentravam no centro da cidade e ao seu redor havia as casas que também por sua vez não seguiam um padrão de construção e de saneamento. A população londrina não estava preparada para sofrer com as alterações climáticas geradas pela ação antrópica. As mudanças climáticas causadas pela ação do homem ao nível local, veio ocasionar problemas à saúde como doenças respiratórias e afetando as parcelas mais sensíveis da população como gravidas, idosos, crianças e cardiopatas. Esses estudos subsidiaram as primeiras concepções metodológicas sobre os Sistema Clima Urbano para a metrópole de São Paulo idealizadas por Monteiro (1976).

SOUZA (2004) informa que as cidades mal planejadas sofrem grandes problemas com o fenômeno da ilha de calor. Essas ocorrem em locais com maior quantidade de construções e baixa concentração de áreas verdes onde a temperatura é mais elevada que áreas vizinhas que tem uma maior concentração de árvores.

O processo de urbanização na cidade de Salvador como em diversas cidades brasileiras não contou com um processo adequado de planejamento de seu sistema viário e da ampliação das áreas construídas. $\mathrm{O}$ crescimento da população urbana impactou na necessidade de novos lugares para moradia, tendendo para a descentralização e formação novas áreas periféricas e novos territórios (LOBATO, 1994).

No entanto as áreas de estudos do clima urbano na cidade vigente é o seu miolo urbano, o qual desencadeou alterações climáticas por conta das interferências introduzidas em seu espaço 
na sua paisagem e dinâmica de seu ambiente natural. Essas mudanças ocasionaram o acréscimo significativo da temperatura do ar nas áreas de maior movimento de pessoas e tráfegos de carros e construções de prédios. Essas alterações induzem a formação de corredores de ventos interferindo no ciclo natural da pluviosidade da cidade.

Como exemplo o bairro de Cajazeiras em sua avenida central, podemos observar como o processo de pavimentação capeou o solo. Sem implementação de áreas verdes para a amenização das altas térmicas gerado pelo baixo albedo.

Na cidade de Salvador em seu PDDU consta várias cláusulas para planejamento urbano, onde consta a qualidade do ambiente urbano, preservação dos recursos naturais e o conforto ambiental, conservação dos recursos dos mananciais hídricos superficiais e subterrâneos de abastecimento de água que seriam essências para a conforto térmico e saúde da população.

Nesta pesquisa será indicada que em alguns bairros da cidade não há nenhum planejamento tanto para a preservação da natureza quanto para a ocupação do solo e sua má ocupação e organização. Essa situação decorre dos efeitos perversos das políticas públicas que vêm contribuindo para as oscilações térmicas na atmosfera e nas superfícies, gerando o microclima para a formação das ilhas de calor em determinados bairros, segundo Estevam e Neri (2019).

Ainda no Plano de Diretor de Desenvolvimento Urbano (2016), consta-se neste documento as diretrizes sobre o conforto ambiental urbano e as condições climáticas, iluminação e ventilação naturais, radiação térmica e ventilação. Condições estas para que a população viva de maneira não insalubre como no início da implantação da cidade de Salvador. Entretanto as políticas públicas não conseguiram realizar em algumas áreas do sitio o que se foi posto pelo Plano Diretor de Desenvolvimento Urbano, pois a urbanização se deu de maneira rápida e voraz, onde a cidade é o cenário dos conflitos de classe. Lócus onde se passam diversos projetos de poder e onde sempre há a possibilidade de intervenções autoritárias, tanto da esfera pública como da privada (Pedrão, 2005).

Com o crescimento urbano há maior necessidade de mão de obra, estimula-se o crescimento demográfico e gera-se mais demandas para suprir a população. Nesta ambiência extrapola-se a capacidade financeira do município, como resultado observam-se inúmeros bairros sem o planejamento adequado. 
Conforme indicado por Pedrão 2005, houve uma inversão de significado e as políticas urbanas ficaram determinadas por sua mecânica e não por sua funcionalidade, é o que ocorre em alguns bairros da cidade da Salvador. As políticas do Plano Diretor de Desenvolvimento Urbano, não estão em funcionamento nas áreas que mais sofrem com estes fenômenos como os bairros de Cajazeiras e a região do Iguatemi que detém um grande fluxo de carros e comércios e uma área densamente pavimentada sem áreas de penetração de água de chuvas no solo e sem lagos ou rios.

Uns e outros significam uma ruptura de escala frente a lojas comerciais e restaurantes independentes, que esvaziam a capacidade de prestação de serviços dos bairros e geram focos de congestionamento. Grandes áreas de favelização consolidada ilustram o modo principal de formação da cidade, que, certamente, é o dos grupos de baixa renda. A principal paisagem da cidade é de tijolos aparentes: a contra paisagem da visão turística da cidade. A saturação dos equipamentos de uso coletivo cria uma norma à qual todos estão submetidos, que é a do congestionamento do tráfego. Novos empreendimentos do grande capital em áreas de transporte saturado levam a perspectivas de bloqueio urbano sem solução. (PEDRÃO, 2005, p. 2 e 3)

\section{ILHAS DE CALOR: ESTUDOS APLICADOS A METRÓPOLE DE SALVADOR}

A algumas características da cidade de Salvador propiciam para o favorecimento das ilhas de calor em determinados bairros. Sua ocupação irregular e a ausência de projetos de arborização e a canalização dos rios urbanos. Essas alterações interferem no clima local ocasionando respostas ambientais no tocante ao ciclo hidrológico e dinâmica das temperaturas do ar.

A expansão mal planejada no sitio urbano de Salvador e as áreas de ocupações sem nenhuma política pública adequada para a organização e alocação das residências geraram assim áreas de riscos e pavimentações sem planejamento, no tocante a estudos de drenagens urbanas para condução das águas pluviais de acordo com ESTEVAM:

Os diferentes tipos de cobertura implicam também em influências drásticas sobre o conforto térmico da cidade. Tais condições resultam no desconforto térmico para as comunidades que residem em bairros ou pontos altamente pavimentados. Nas zonas detentoras de grandes áreas 
de pavimento asfáltico com exacerbadas estruturas de concreto e fluxo intenso de veículos promovem em sua interação com a atmosfera, baixo grau de Albedo. (ESTEVAM, 2019, p.43).

As Ilhas de calor tornam-se um fenômeno ligado inteiramente e exclusivamente com o processo de urbanização, sendo um fenômeno como posto por (OLIVEIRA, 2019, p. 5) as atividades antropogênicas, os materiais artificiais produzidos para atender as demandas da sociedade se somam, e alteram a dinâmica atmosférica, provocando mudanças nos padrões energéticos e hídricos do espaço que passa a ser urbanizado.

Nas áreas que se encontram resquícios de mata o uso irregular do solo traz consequências futuras como deslizamentos e erosão do solo. A ocupação irregular nas áreas de risco vai trazer agravantes futuros. Neste sentido, as construções mal planejadas e a pavimentação desreguladas são futuros propulsores das ilhas de calor.

De acordo com Estevam e Neri em seu trabalho de campo no sistema urbano de Salvador entre os anos de 2018 e 2019 ,

Então, as ilhas de calor resultam da elevação da temperatura média na zona urbana (áreas centrais), ocorrendo pela diferença de irradiação de calor entre as regiões edificadas, regiões onde há cobertura vegetal e há esse contraste de temperatura, regiões com alta concentração de poluentes, e zonas centrais das cidades. (ESTEVAM E NERI, 2019, p.146)

Torna-se um fenômeno encontrado apenas em áreas de maior massa urbana, estas áreas tem um maior teor de aumento da temperatura, formando um microclima exclusivo daquela área, este fenômeno se torna perceptivo á pessoas das áreas urbanas devido ao aumento do desconforto térmico, gerando assim mal-estar, segundo NERI:

Pode ser definido o conforto térmico em um ambiente, como a sensação de bem-estar experimentado por uma pessoa, como resultado da combinação satisfatória, neste ambiente, da temperatura radiante média, umidade relativa, temperatura ambiente e velocidade relativa do ar, com as atividades desenvolvidas e com a vestimentas usadas por estas pessoas. As sensações são subjetivas, isto é, depende das pessoas (certo ambiente confortável termicamente para uma pessoa pode ser frio ou quente para outra). Assim, entende-se como condições ambientais de conforto aquelas que propiciam bem-estar ao maior número possível de pessoas. (NERI, 2019, 
p. 144)

\section{IMPACTOS DAS ILHAS DE CALOR NO CONFORTO TÉRMICO}

Vários estudos têm apontado para interferência das ilhas de calor no conforto térmico nas grandes e médias cidades. Considera-se que as reações das pessoas ao frio ou calor tem repercussão direta sobre a saúde das pessoas, nas políticas públicas, de rentabilidade no trabalho, do consumo de energia na sociabilidade e de forma geral na qualidade de vida.

Para García (1995 citado por Gomes e Amorim, 2003, p. 96), o "conforto térmico consiste no conjunto de condições em que os mecanismos de auto-regulação são mínimos ou ainda na zona delimitada por características térmicas em que o maior número de pessoas se manifeste sentir bem". Se o ambiente não oferece condições térmicas agradáveis a um indivíduo ou para a população tem-se então o desconforto térmico.

Variáveis individuais e ambientais podem influenciar no conforto térmico. Dentre as primeiras destacam-se as características das vestimentas e do metabolismo (sexo, idade, raça, atividade exercida e hábitos alimentares), o que pode mudar substancialmente as preferências térmicas de pessoa para pessoa (SILVA, 2008). Dentre as variáveis ambientais, a temperatura, a umidade relativa ar e a velocidade do vento têm grande importância para a determinação das diferentes faixas de conforto. Na área da Climatologia Urbana, tem-se dado maior importância para estudo das variáveis ambientais. Estas variáveis, segundo Frota e Schiffer (2003, p. 15): "Guardam estreitas relações com regime de chuvas, vegetação, permeabilidade do solo, águas superficiais e subterrâneas, topografia, entre outras características locais que podem ser alteradas pela presença humana".

\section{CARACTERÍSTICAS GEOGRÁFICAS DE SALVADOR}

Salvador está localizada na região do Recôncavo Baiano o município possui 2.7 milhões de habitantes tendo uma área de 4 375,123 quilômetros quadrados. Está localizada em uma área de dois patamares geológicos de elevação onde se caracteriza a cidade alta que está no topo e a baixa em patamar inferior.

A cidade situa-se entre as coordenadas geográficas: $12^{\circ} 58^{\prime} 16^{\prime \prime} \mathrm{S}$ e $38^{\circ} 30^{\prime} 39^{\prime \prime} \mathrm{W}$ banhada 
pelo Oceano Atlântico, tem ao sul e a oeste a Baía de Todos os Santos, como pode ser observado na Figura 1. Devido suas características de tropicalidade a região é influenciada pelos ventos alísios que sopram permanentemente de leste com variações de nordeste e de sudeste, sendo este o vento predominante da grande escala na região. Por outro lado, o corpo d'água representado pela Baía de Todos os Santos interfere tanto na oferta de umidade como para circulação atmosférica (CARDOSO 2017 p.19).

Figura 1. Mapa de localização da cidade de Salvador.

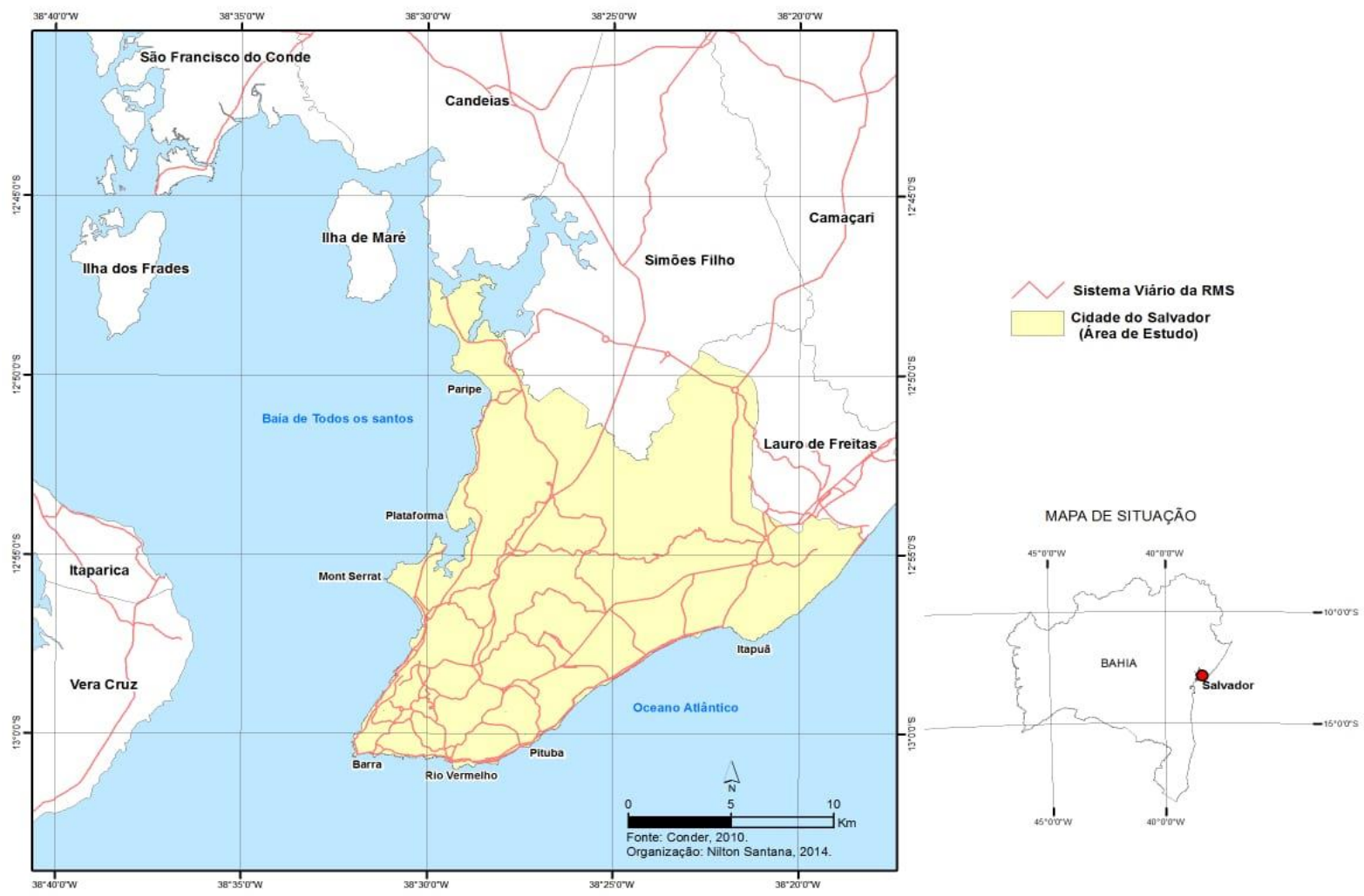

Fonte: Santana, N. Tese de Doutorado. IGEO/UFBA, (2014).

Segundo Cardoso (2017) suas características climáticas são: alta pressão subtropical do atlântico sul; ação permanente dos ventos alísios; localização na faixa tropical da América do Sul; próxima ao oceano atlântico favorecendo as águas relativamente quente durante o ano.

\section{Metodologia}

Para produção deste artigo foram empregadas concepções teóricas elaboradas por Monteiro 
(1976). As discussões pioneiras desenvolvidas pelo referido autor contribuíram para este estudo permitindo-se avaliar os efeitos danosos da urbanização mal planejada e seus efeitos sobre o aquecimento das superfícies e por consequente do ar circunjacentes nos grandes centros urbanos.

Para esta análise foram realizados estudos em diversos artigos, teses e dissertações que trabalharam metodologias e investigações diversas sobre o tema das ilhas de calor.

Foram realizados em campo tomadas de temperatura das superfícies representativas dos tipos de cobertura dos solos. Dentre as principais superfícies analisadas destacaram-se o asfalto, superfícies de concreto, solo exposto, coberturas de grama e sombra de árvores. As tomadas de temperaturas foram realizadas com termômetros constituídos de sensores de infravermelho. $\mathrm{O}$ período de ocorrência das tomadas de temperatura ocorreu na estação do verão no mês de fevereiro do ano de 2019. O período do dia das tomadas de temperatura correspondeu às 11:30. Os dias encontravam-se com baixo recobrimento de nuvens e forte insolação.

Para melhor estudar as ilhas de calor e sua magnitude foram analisados os dados de temperatura do ar geradas pela estação meteorológica do Instituto Nacional de Meteorologia (INMET), localizada no bairro de Ondina na Orla Atlântica de Salvador para o período de 2017 à 2019. Para representação das áreas mais distantes da orla marítima foram averiguados dados produzidos pela estação meteorológica automatizada da empresa CETREL localizada na Avenida Antônio Carlos Magalhães - DETRAN.

Foram averiguadas algumas correlações de dados das temperaturas do ar gerados pelo $4^{\circ}$ Distrito de Meteorologia (DISME/INMET) com os dados resultantes da medição in loco das temperaturas das superfícies. Essas informações foram analisadas de forma interativa com o clima local para identificar os elementos do clima que mais influenciam nas ilhas de calor. Como por exemplo, a temperaturas do ar, umidade relativa do ar e velocidade dos ventos.

\section{Resultados}

A cidade de Salvador por estar localizada em área litorânea possui características de clima local muito relevantes para amenização dos efeitos das ilhas de calor. Detém efeito de brisas marítimas importantes que conferem frescor através de ventos que circulam do oceano Atlântico e baía de Todos os Santos em direção ao continente. Efeitos de frescor e conforto 
térmico são percebidos nas avenidas litorâneas. No entanto, ao longo do miolo urbano a realidade térmica é bem diferenciada. Tal realidade decorre do efeito barlavento produzido pela linha de construção dos edifícios que interrompem a circulação das brisas do oceano em direção ao centro da cidade.

Tabela 1: tabela de medidas da velocidade do vento, da temperatura mínima e máxima e da umidade relativa.

\begin{tabular}{|c|c|c|c|c|c|}
\hline Ano & $\begin{array}{c}\text { Velocidade do } \\
\text { vento média }(\mathrm{m} / \mathrm{s})\end{array}$ & $\begin{array}{l}\text { Temperatura } \\
\text { máxima média } \\
\left({ }^{\circ} \mathrm{C}\right)\end{array}$ & $\begin{array}{c}\text { Temperatura } \\
\text { mínima média } \\
\left({ }^{\circ} \mathrm{C}\right)\end{array}$ & $\begin{array}{c}\text { Temperatura } \\
\text { compensada } \\
\text { média }\left({ }^{\circ} \mathrm{C}\right)\end{array}$ & $\begin{array}{c}\text { Umidade } \\
\text { Relativa do ar } \\
(\%)\end{array}$ \\
\hline 2017 & 0,86 & 29,05 & 22,21 & 25,30 & 83,99 \\
\hline 2018 & 0,79 & $30,95^{2}$ & $23,74^{4}$ & $26,80^{5}$ & $79,26^{7}$ \\
\hline 2019 & $0,72^{1}$ & $29,43^{3}$ & 24,00 & $26,00^{6}$ & $80,37^{8}$ \\
\hline
\end{tabular}

${ }^{1}$ : Referente a 9 meses; ${ }^{2}$ : Referente a 6 meses; ${ }^{3}$ : Referente a 9 meses; ${ }^{4}$ : Referente a 6 meses; ${ }^{5}$ : Referente a 6 meses; ${ }^{6}$ : Referente a 9 meses; ${ }^{7}$ : Referente a 6 meses; ${ }^{8}$ : Referente a 9 meses. Fonte: INMET 2020.

Na Tabela 1 pode ser observado a velocidade média dos ventos, temperatura máxima média e mínima média dos anos 2017, 2018 e 2019, onde podemos observar a crescente alta da temperatura anual, da cidade de Salvador, portanto constatando o fenômeno das IC já que a cidade está em constantes crescimento urbano e, portanto, com uma maior necessidade de ocupação do sitio para atender as demandas de crescimento.

A situação geográfica da cidade em associação a eliminação da cobertura vegetal natural, conforme observado na Figura 2 produz o efeito de aquecimento das superfícies e atmosfera em microescala. No mapa observa-se apenas remanescentes com Floresta Ombrófila, vegetação de brejos, restingas e manguezais. Enquanto que a área urbanizada predomina em todo o território urbano da cidade.

$\mathrm{Na}$ área urbanizada encontra-se revestimento extensivo das superfícies por vias de asfalto de cor negra, viadutos de concreto, calçamentos de cor negra e fluxo intenso de veículos. Devido a composição e extensão dessas superfícies se aquecem com extrema rapidez no período de setembro a fevereiro.

Figura 2. Mapa de usos dos solos da cidade de Salvador, BA. Extensão predominante da área 
urbanizada com relação as formações vegetais.

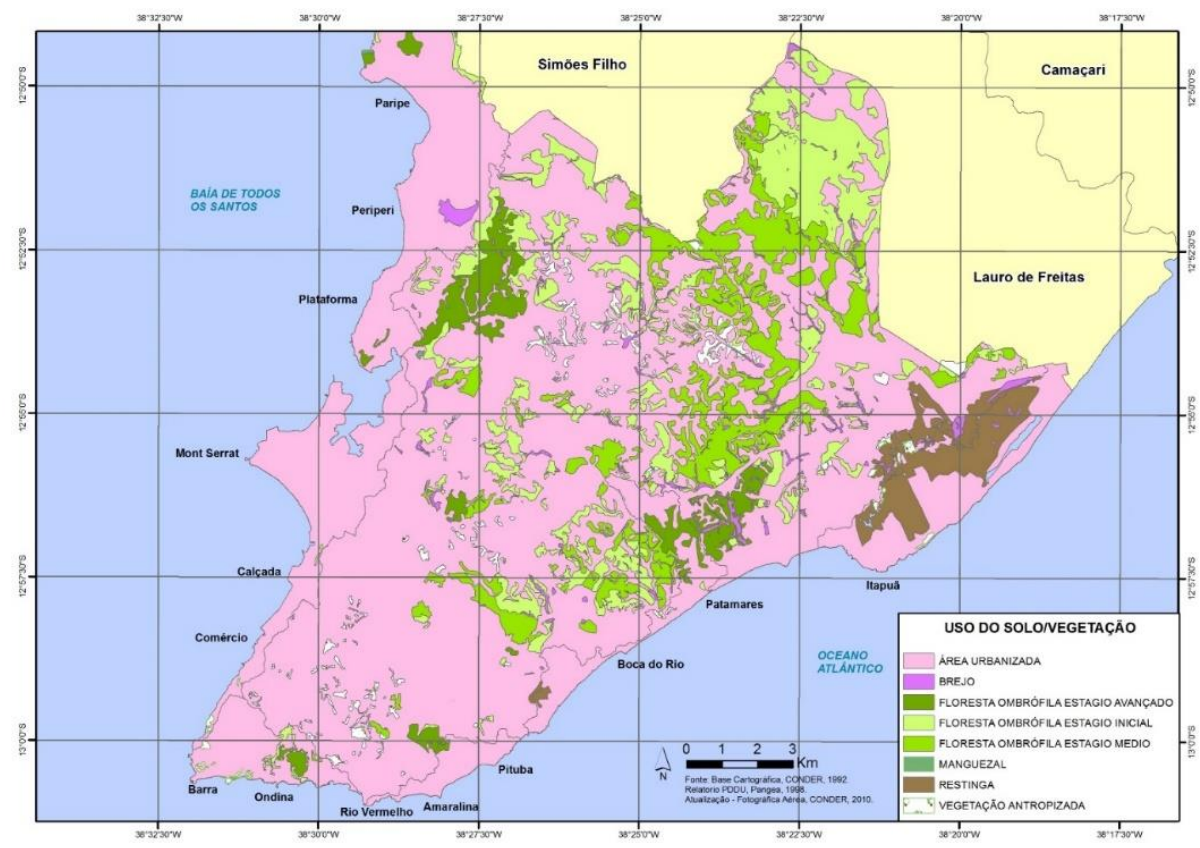

Fonte: Relatório PDDU, Pangea.1998.

A intensa urbanização associada as alterações do modo de uso e ocupação do solo deve ser levada em consideração no planejamento urbano, já que o avanço excessivo pode influenciar em um aumento da temperatura na superfície, prejudicando a qualidade de vida das pessoas que usam a região para moradia ou para outra atividade (ESTEVAM E NERI 2019).

A partir das análises estabelecidas nos trabalhos de Cardoso (2017) no qual foram referenciados as médias de temperaturas do ar entre os anos de 2013 a 2016 . Foi identificado as localidades com as maiores temperaturas, constituem os bairros Rio Vermelho e ACMDETRAM onde as ilhas de calor são mais intensas. No bairro de Ondina as medias anuais são mais reduzidas devido ao favorecimento das características naturais lá encontradas. Nesta localidade são observados resíduos de Florestas Ombrófila. No bairro atuam sistemas de brisas eficientes na linha de costa. Essas características ambientas tornam o bairro da Ondina uma ilha de frescor. Enquanto que as áreas mais afastadas como Avenida ACM-DETRAN indicam aquecimento da atmosfera em virtude do asfaltamento e impermeabilização extensiva dos solos.

Tabela 2: Temperatura média do ar em estações meteorológicas de Salvador. 
Fonte: Elaborado por (CARDOSO 2017, p.32)

\begin{tabular}{lccccc}
\hline \multirow{2}{*}{ Localização } & \multicolumn{5}{c}{ Temperatura do ar (média anual) ${ }^{\circ} \mathbf{C}$} \\
& $\mathbf{2 0 1 3}$ & $\mathbf{2 0 1 4}$ & $\mathbf{2 0 1 5}$ & $\mathbf{2 0 1 6}$ & Média \\
\hline ONDINA - Rural de referência & 25,7 & 25,0 & 25,9 & 26,3 & 26,0 \\
RIO VERMELHO - Urbana 1 & 27,1 & 27,0 & 27,4 & 27,3 & 27,2 \\
ACM - DETRAN - Urbana 2 & 26,9 & 26,9 & 27,3 & 27,5 & 27,2 \\
PARALELA-CAB - Urbana 3 & 25,9 & 25,7 & 26,2 & 27,0 & 26,1 \\
\hline
\end{tabular}

Figura 3. Fotografia do Alto de Ondina, Salvador.

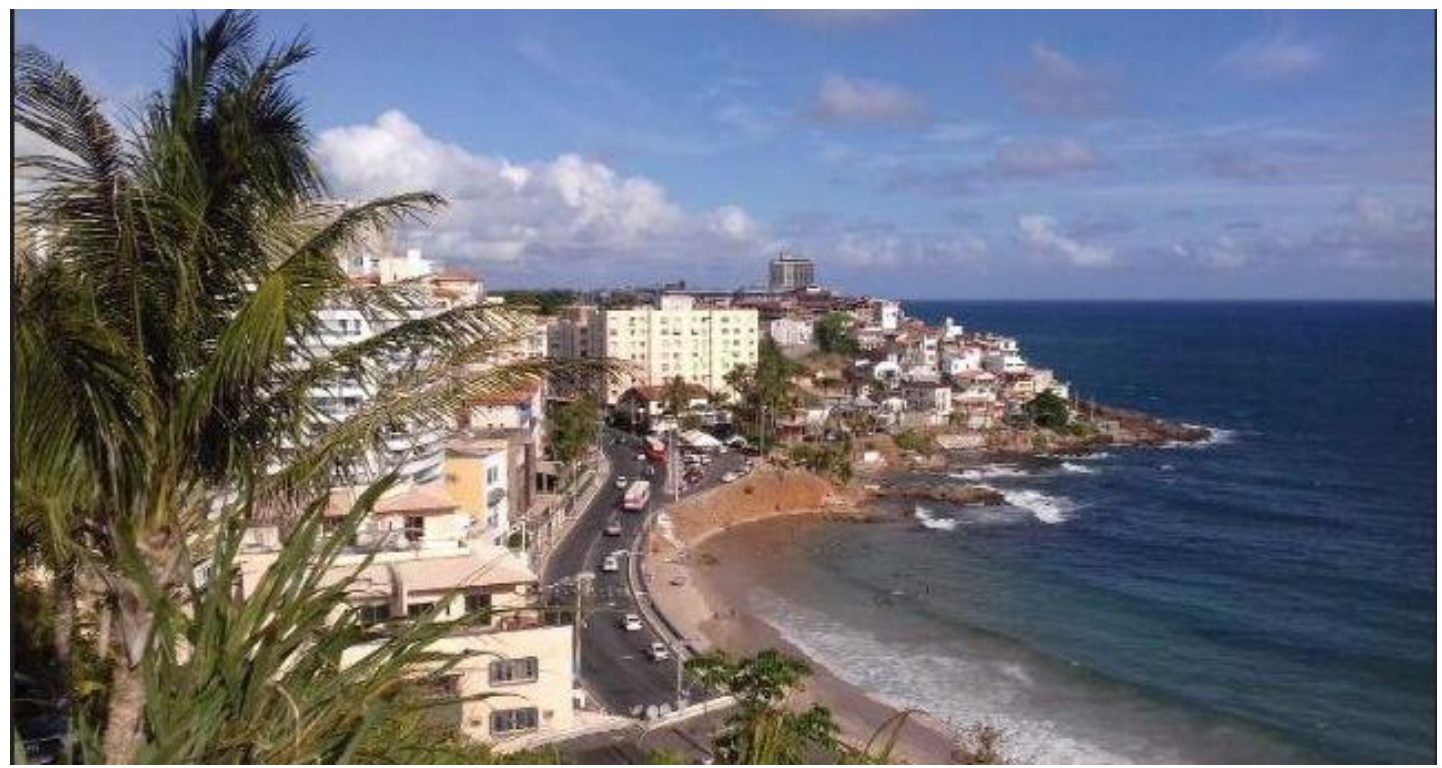

Fonte: Trabalho de campo realizado em novembro de 2019. Relatório da Pesquisa.

O Alto de Ondina na Figura 3 mostra como o sistema de barlavento funciona na dinâmica de aquecimento da parte interna dos bairros. As disposições dos prédios não favorecem a circulação das brisas marítimas para o interior no miolo urbano. Neste sentido, os bairros centrais da cidade sofrem o efeito mais intenso do aquecimento, tendo em vista não possuir o efeito aprazível da circulação de ventos marítimos.

Tabela 3. Uso, ocupação dos solos, materiais e albedo. Indicadores de aquecimento das 
superfícies.

\begin{tabular}{lcccc}
\hline \multicolumn{1}{c}{ Área Analisada } & $\begin{array}{c}\text { Tipos de } \\
\text { superfície }\end{array}$ & Temperatura C $^{\circ}$ & $\begin{array}{c}\text { Cor da } \\
\text { superfície }\end{array}$ & Albedo \\
\hline Avenida Sete & Asfalto & 32.6 & Negra & Baixo \\
R. Do Iguatemi & Concreto & 62.8 & & \\
Avenida Sete & & 41.4 & Cinza & Baixo \\
R. Do Iguatemi & Solo exposto & -- & Vermelho e & Baixo \\
Avenida Sete & & 40.9 & Laranja & \\
R. Do Iguatemi & Sombra de árvore & 29.0 & Negra & Elevado \\
Avenida Sete & & 31.7 & & \\
R. Do Iguatemi & & 31.7 & Laranja & Elevado \\
Avenida Sete & Pedra portuguesa & 50.8 & & \\
R. Do Iguatemi & & -- & Verde & Elevado \\
Avenida Sete & Grama & 44.5 & & \\
R. Do Iguatemi & & & & \\
\hline
\end{tabular}

Fonte: Trabalho de campo. Projeto Sistema Clima Urbano 12.2019.

A tabela acima mostra os materiais que retém e absorve mais calor durante o dia, materiais como asfalto, concreto, solo exposto, sombra de árvore, pedra portuguesa e grama, foi observado que na região do Shopping Bahia (antigo Iguatemi) como área urbanizada e Avenida Sete de setembro. Foi observado que os materiais como asfalto e pedra portuguesa que retém o calor propulsor das ilhas de calor, tornando assim as temperaturas do ar mais elevadas.

Temos como resultado das analise das obras, o aumento significativo das ilhas de calor em bairros como Iguatemi, Rio Vermelho, Cajazeira e Av. Antônio Carlos Magalhães (ACMDETRAN), pelo processo de urbanização e as construções e pavimentações e impermeabilização do solo em excesso, assim gerando uma maior absorção da radiação solar em alguns tipos de superfícies como: asfalto, concreto e pedra portuguesa e o trafego intenso de carros propulsionam, também para o favorecimento do fenômeno. Na Figura 4, podemos observar como o revestimento da superfície do solo na Av. Antônio Carlos Magalhães representa as características do microclima das ilhas de calor.

A partir deste ponto de referencial das características do rural e urbano, podemos pensar em uma nova política pública para inserir no contexto da cidade a inserção de árvores e gramíneas em bairros onde o fenômeno das ilhas de calor são mais elevados, já que este é um 
fenômeno ligado inteiramente ao modo de ocupação do solo e transformação das características naturais que ali foram existentes.

Figura 4. Fotografia da Avenida Antônio Carlos Magalhães. Área altamente urbanizada.

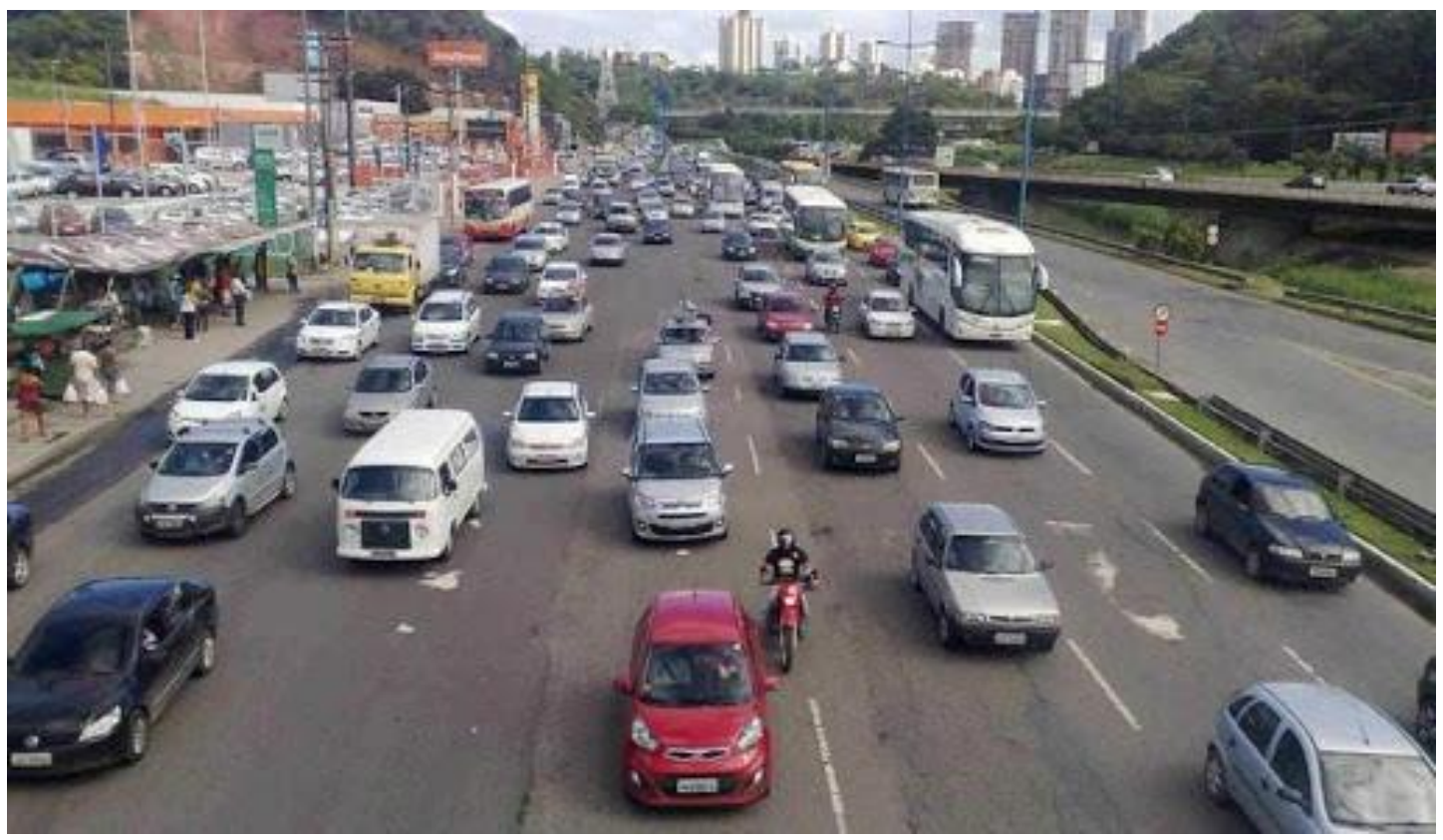

Fonte: Trabalho de campo realizado em novembro de 2019. Relatório da Pesquisa.

A partir do exposto, conclui-se que relevantes gradientes térmicos da superfície entre as áreas e suas coberturas, podem indicar diferença de $30,2{ }^{\circ} \mathrm{C}$ no caso do asfalto, por exemplo, onde a cobertura de asfalto registrou $32,6^{\circ} \mathrm{C}$ na Avenida Sete de Setembro e na área do Iguatemi apresentou $62,8{ }^{\circ} \mathrm{C}$. Demonstrou-se que a vegetação interfere diretamente para amenizar a absorção do calor na superfície. Fato observado na Avenida Sete de Setembro, na qual identificou-se bom recobrimento por árvores.

A partir da análise feita para o conforto térmico compreendendo a variável de cada indivíduo de acordo com as vestimentas e as características fisiológicas de cada indivíduo essas variantes são: sexo, idade, raça, atividade exercida e hábitos alimentares (SILVA 2008, SOUZA E NERY, 2012). 
Tabela 4 - Classificação do Índice de Desconforto, segundo García (1995).

\begin{tabular}{|c|c|c|c|}
\hline TTE & $\begin{array}{l}\text { Sensação } \\
\text { Térmica }\end{array}$ & Conforto & Resposta Física \\
\hline $440^{\circ} \mathrm{C}$ & Muito quente & Muito incômodo & $\begin{array}{l}\text { Problemas de regulação Aumento da tensão por } \\
\text { transpiração e aumento fluxo sanguíneo }\end{array}$ \\
\hline $335^{\circ} \mathrm{C}$ & Quente & & $\begin{array}{c}\text { Aumento da tensão por transpiração e aumento fluxo } \\
\text { sanguíneo }\end{array}$ \\
\hline $330^{\circ} \mathrm{C}$ & Temperado & & Regulação normal por transpiração e troca vascular \\
\hline $225^{\circ} \mathrm{C}$ & Neutro & Cômodo & Regulação vascular \\
\hline $220^{\circ} \mathrm{C}$ & $\begin{array}{l}\text { Ligeiramente } \\
\text { fresco }\end{array}$ & $\begin{array}{l}\text { Ligeiramente } \\
\text { cômodo }\end{array}$ & Aumento as perdas por calor seco \\
\hline $115^{\circ} \mathrm{C}$ & Frio & Incômodo & Vasoconstrição nas mãos e nos pés \\
\hline $110^{\circ} \mathrm{C}$ & Muito frio & & Estremecimento \\
\hline
\end{tabular}

Fonte - García (1995) apud Gomes e Amorim (2003).

O índice de desconforto tem sua variante nas caraterísticas fisiológicas de cada indivíduo, a depender da sensação térmica, este indivíduo pode apresentar problemas. Na tabela acima apresenta a sensação térmica e as respostas físicas, "o índice ideal próximo a $25,0^{\circ} \mathrm{C}$ é considerado como a faixa de conforto ideal para o ser humano. Acima deste valor a situação tende-se a apresentar desconfortável devido ao calor, além de levar os indivíduos a desenvolver problemas de regulação vascular" (SOUZA E NERY 2012, p. 74).

A partir das tomadas de temperaturas das superfícies produzidas pela pesquisa do projeto sistema clima urbano e de suas correlações com as temperaturas do ar produzidas pelas estações meteorológicas em diversos pontos da cidade. Observou-se que os dados produzidos em correlação com o Índice de Desconforto Térmico proposto por Garcia. Identificou-se que todas as áreas produzem condições de Desconforto Térmico Incômodo. Ressaltando-se que a cidade detém Ilhas de Calor difusas. Excetuando-se nas áreas de orla marítima, todos os bairros da cidade estão submetidos ao efeito das ilhas de calor.

Todas as áreas submetidas às ilhas de calor estão classificadas na categoria de Desconforto Térmico Incômodo que interferem diretamente para saúde das pessoas com impactos negativos para pressão arterial. 


\section{Conclusões}

Na Tabela 2 a partir de dados compilados em artigos, teses e da $4^{\circ}$ DISME/INMET sobre as temperaturas do ar. Identificou-se a necessidade de uma nova reurbanização para áreas como o Iguatemi, Rio vermelho e ACM-DETRAN, pois são áreas que foram identificados microclimas das ilhas de calor intensas. As temperaturas do ar encontram-se muito elevadas. E não há nenhuma ação para mitigação no Plano Diretor de Desenvolvimento Urbano do Município de Salvador. Algumas metodologias de mitigação das ilhas de calor nas localidades referenciadas carecem de implementação urgente para amenização do microclima, como a troca do material asfáltico e usos das cores claras, o plantio de árvores e grama.

Entende-se que o PDDU (2016) em suas cláusulas que foram postas para amenizar os efeitos das ilhas de calor não estão sendo introduzidas. Nenhuma das medidas, como por exemplo, de arborização e das trocas dos materiais de pavimentações e dos pisos de cores escuras para cores claras foram efetuadas. Tais medidas poderiam em muito amenizar o efeito da temperatura e para o favorecimento da circulação do ar.

Para atenuar os efeitos perversos das ilhas de calor se faz necessário a introdução de políticas públicas com alterações na paisagem urbana para um melhor conforto térmico. Entende-se que o conforto é decorrente da sensibilidade das pessoas. É necessário que ocorram ações para amenizar o desconforto dos aumentos de temperaturas no decorrer do verão. Com adoção das seguintes medidas:

I - Pela adoção de revestimentos das superfícies dos planos horizontais e verticais, de reconhecida capacidade de redução térmica, como uso de cores claras, espécies gramíneas e arbóreas, aumentando a capacidade de reflexão da radiação, associada às condições de ventilação urbana;

II - Pelos canais formados pela configuração e implantação dos edifícios, que podem evitar o aquecimento do ambiente urbano;

III - Pelas transformações na configuração física da forma urbana, produzidas a partir das diversas relações estabelecidas entre edifícios e espaços abertos, que podem contribuir para a melhoria da qualidade do clima urbano; 
IV - Pela assimetria da forma urbana criada pelas diferenças de altura entre edifícios próximos, trazendo benefícios para o conforto do pedestre, e a ventilação natural no interior dos edifícios e, consequente dispersão de poluentes do ambiente urbano;

V - Pela inserção do edifício no terreno, incluindo o tratamento por pilotis, marquises e articulações da forma arquitetônica, como medidas para aproximar o edifício da escala humana, para proteger o nível térreo contra o sol, a chuva e o vento, permitindo a passagem do vento ao redor dos edifícios e sob ele.

Após a análise dos aspectos geográficos relacionados ao sistema clima urbano conclui-se que o processo de urbanização acelerado e generalizado associado à impermeabilização dos solos e substituição da floresta ombrófila por estruturas de concreto são os principais fatores que atuam constantemente na ocorrência das ilhas de calor, sobretudo no miolo urbano da cidade. Mediante as análises e resultados encontrados neste artigo destacamos que para a mitigação dos efeitos das ilhas de calor é necessário um sistema de planejamento urbano que priorize arborização das áreas centrais para a amenização das ilhas de calor.

\section{Agradecimentos}

Agradecimentos ao grupo de pesquisa cidades problemas ambientais e sustentabilidade nas cidades médias do Recôncavo Baiano. Agradecimentos à Fundação de Amparo à Pesquisa do Estado da Bahia (FAPESB) pela concessão de bolsas de iniciação científica para esta pesquisa.

\section{REFERÊNCIAS:}

MONTEIRO, C. A. F. (1971). Análise Rítmica em Climatologia: problemas da atualidade climática em São Paulo e achegas para um programa de trabalho. São Paulo: IGEOG/USP.

MONTEIRO, C. A. F. (1976). Teoria e Clima Urbano. Série Teses e Monografias, n. 25. São Paulo: Universidade de São Paulo.

LOMBARDO, M. A. (1985). Ilhas de Calor nas Metrópoles: o exemplo de São Paulo. São Paulo: Hucitec.

MONTEIRO, C. A. F. (1990). A cidade como processo derivador ambiental e a geração de um clima urbano - Estratégias na abordagem geográfica. Geosul, n. 9, v. 1. p. 80 - 114. 
MONTEIRO, C. A. F. (2001). Geossistemas - História de uma procura. São Paulo: Editora Contexto. v.01. $154 \mathrm{p}$.

Gartland, L. (2010). Ilhas de Calor como Mitigar Zonas de Calor em Áreas Urbanas (Oficina de Textos, São Paulo), 248p.

SANTANA, N. S. (2014). Análise da vulnerabilidade ambiental de Salvador: um subsídio ao planejamento e a gestão territorial da cidade. Programa de Pós-Graduação em Geologia. Universidade Federal da Bahia.

CARDOSO, L. (2017). Estudo do microclima urbano a partir de plataformas de coleta de dados (pcd's) da fachada sudeste de salvador. Ano 2017. 81f. Universidade Federal da Bahia, Salvador.

ESTEVAM, A. L. \& SANTOS, R. M. dos. (2017). Sistema clima urbano e contribuições ao estudo das áreas de risco na cidade de Salvador. In. Simpósio Brasileiro de Climatologia Geográfica. [S. 1.], p. 1-10.

ESTEVAM, A. L. D. NASCIMENTO, A. S. SANTOS, R. M. et al. (2019). Climatologia geográfica e impactos ambientais urbanos na cidade de Salvador. Santo Antônio de Jesus: Lab Cria e Conecta

ESTEVAM, A.L \& OLIVEIRA, J. (2019). Ilhas de Calor no bairro de Cajazeiras: Estudo de caso na cidade de Salvador, Bahia-Brasil. Santo António de Jesus. v.3, n.2.

IBGE - INSTITUTO BRASILEIRO DE GEOGRAFIA E ESTATÍSTICA (2020). Estatísticas $<$ https://www.ibge.gov.br/cidades-e-estados/ba/salvador.html $>$. Acessado em 12 de fevereiro de 2020 .

INMET - INSTITUTO NACIONAL DE METEOROLOGIA. (2020). Conforto térmico humano. Disponível em: <http://www.inmet.gov.br/html/clima/conforto term/index.html $>$. Acessado em 04 de maio de 2020.

PEDRÃO, Fernando. A urbanização voraz em Salvador. Ano 1V. № 5 - outubro de 2019. Disponível em: $<$ http://www.veracidade.salvador.ba.gov.br/v5/pdf\%5Cartigol.pdf $>$. Acessado em 11 de dezembro de 2019.

GOMES, M. A. S. \& AMORIM, M. C. C. T. Arborização e conforto térmico no espaço urbano: estudo de caso nas praças públicas de Presidente Prudente (SP). Caminhos de Geografia, v. 7, n. 10, p. 94-106, set. 2003. Disponível em:

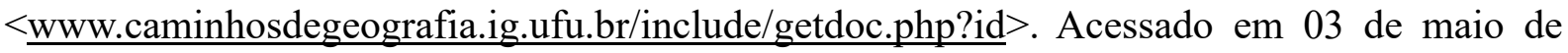
2020.

Lei No 9.069/2016 de 30/06/2016 - Dispõe sobre o Plano Diretor de Desenvolvimento Urbano do Município de Salvador - PDDU 2016 e dá outras providências.

PAGNOSSIN, E. M.; BURIOL, G. A.; GRACIOLLI, M. A. Influência dos elementos 
meteorológicos no conforto térmico humano: bases biofísicas. Disciplinarum Scientia. Série: Ciên. Biol. e da Saúde, Santa Maria, v. 2, n. 1, p. 149-161, 2001. Disponível em: $<\underline{\text { http://sites.unifra.br/Portals/36/CSAUDE/2001/influencia.pdf }>}>$. Acessado em 05 de maio de 2020 .

SILVA, N. R. Avaliação do conforto térmico. 2008. Trabalho de Conclusão de Curso (Engenharia de Segurança do Trabalho) - Universidade Santa Cecília, Santos. Disponível em: $<$ http://www.ergopro.com.br/downloads/monografia.pdf $>$. Acessado em 03 de maio de 2020.

\section{Direitos autorais (Copyrights)}

Financiamento: Este trabalho não recebeu nenhum financiamento.

Conflitos de interesse: Todos os autores declaram não haver conflitos de interesses.

Aprovação do comitê de ética: Não aplicável.

Disponibilidade dos dados da pesquisa: Todos os dados gerados ou analisados neste estudo estão incluídos no manuscrito ou na seção 'materiais complementares/quando houver'.

Contribuição dos autores: Idealização, investigação e execução da pesquisa: SILVA, T. V. S.; OLIVEIRA, L. M. Condução, revisão metodológica, correção e revisão total do manuscrito: SILVA, T. V. S.; CORREIA, L. S.; OLIVEIRA, L. M. 